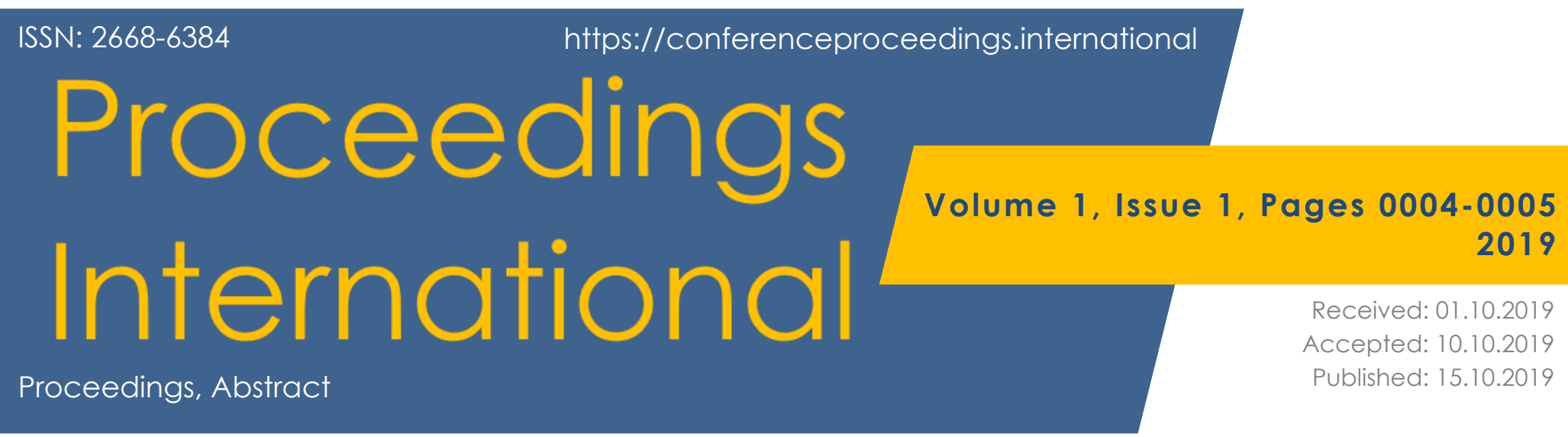

\title{
Electrospun fibers for biomimetic applications
}

\author{
M. Beregoi ${ }^{1}$, A. Evanghelidis ${ }^{1}$, E. Matei ${ }^{1}$, V. Diculescu 1 ${ }^{1}$ I. Enculescu 1,* \\ 1 National Institute of Materials Physics, Str. Atomistilor nr. 405A, Magurele, 077125, Romania \\ * Correspondence: encu@infim.ro; Scopus ID: 6603938022
}

Electrospinning represent a "classic" technique to obtain micrometer and sub micrometer fibers for a wide range of applications. The technique is relatively simple and allows the preparation of industrial amounts of material with low cost. A polymer solution droplet is exposed to an intense electric field which leads to the formation of a jet and further to a very thin fiber of the polymer.

Functionalization represents a step which can tremendously increase the range of applications of these thin fibers. Therefore our aim was to test several paths towards new and more complex architectures. In the present report we will describe our work regarding functionalized biocompatible fiber arrays based on a set of preparation methods which start with electrospinning. In order to achieve the desired functionality sputtering of a thin metal layer leads to conductive fibers. We used these as working electrodes for electrochemical deposition and the fibers were covered with polymers such as polyaniline[1,2] or with $\mathrm{ZnO}$. The sequence of steps enabled us to obtain mats with either electroactive properties or with photocatalytic activity.

Both these properties are very interesting for applications ranging from artificial muscles to substrates with antimicrobial activity. The straightforward, scalable methods of fabrication make the approach a very interesting one for lucrative applications.

Keywords: electrospinning, photocatalytic activity, artificial muscles, antimicrobial activity, biomimetic applications.
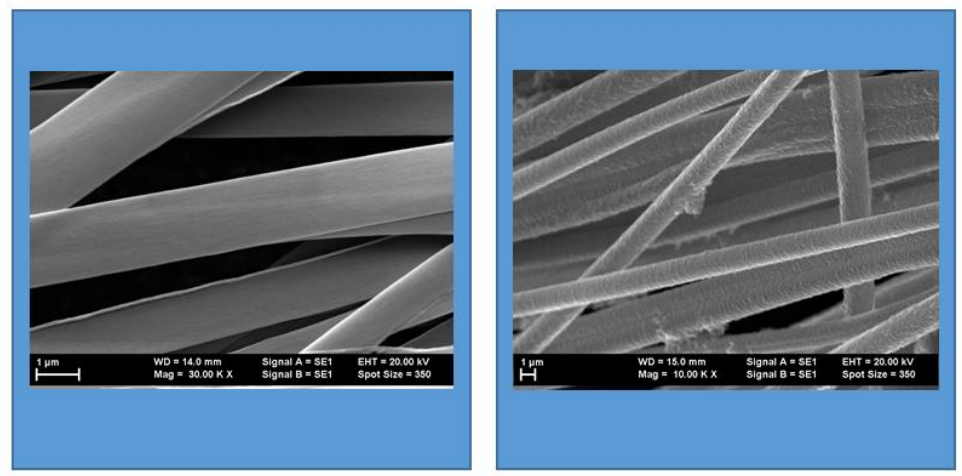

Figure 1. Polypyrrole covered microribons and polyaniline tubes for artificial muscle applications.

PROCEEDINGS INTERNATIONAL | https://conferenceproceedings.international | 4

Cite This Work: Beregoi, M.; Evanghelidis, A.; Matei, E.; Diculescu, V.; Enculescu, I. Electrospun fibers for biomimetic applications. Proceedings Int 2019, 1, 0004-0005.

https://doi.org/10.33263/Proceedings11.00040005 

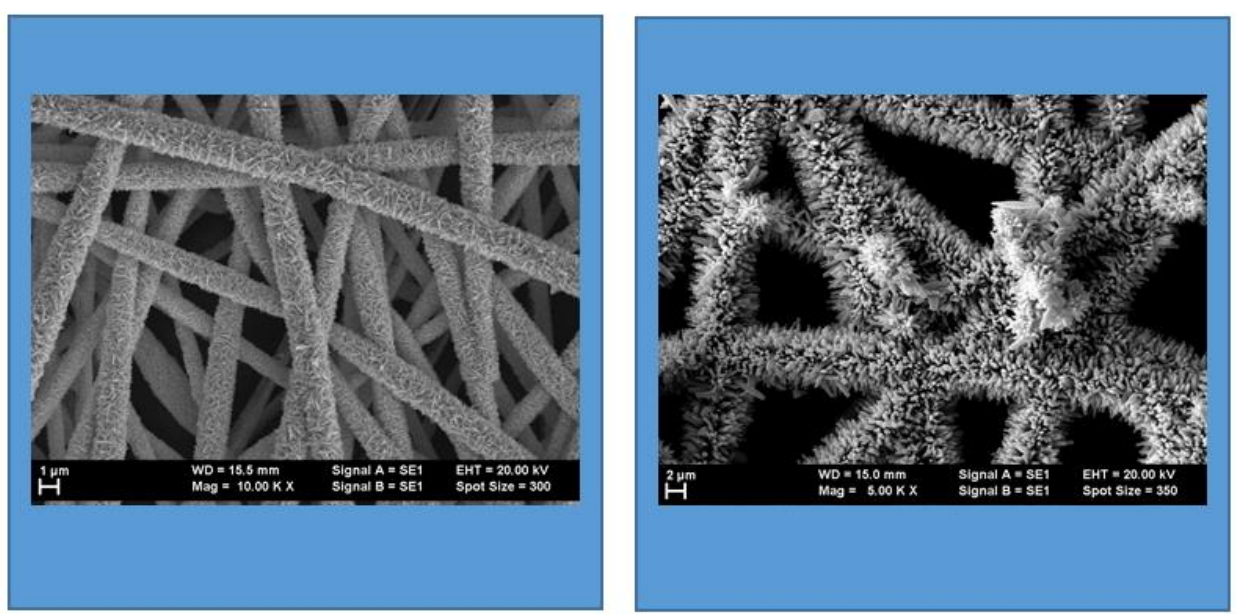

Figure 2. Electrodeposited palladium/palladium oxide and zinc oxide nanostructures for sensing applications.

\section{References}

1. Beregoi, M.; Busuioc, C.; Evanghelidis, A.; Matei, E.; Iordache, F.; Radu, M.; Dinischiotu, A.; Enculescu, A. Electrochromic properties of polyaniline-coated fiber webs for tissue engineering applications.

J. Pharm. 2015, 510, 465-73, https://doi.org/10.1016/j.ijpharm.2015.11.055.
2. Beregoi, M.; Evanghelidis, A.; Matei, E.; Enculescu, I. Polyaniline based microtubes as building-blocks for artificial muscle applications, Sensors Actuators, B Chem. 2017, 253, 576-583, https://doi.org/10.1016/j.snb.2017.06.128.

(C) 2019 by the authors. This article is an open access article distributed under the terms and conditions of the Creative Commons Attribution (CC BY) license (http://creativecommons.org/licenses/by/4.0/). 